Home | Archives | About | Login | Submissions | Notify | Contact | Search

Copyright $\odot 2000$ by The Resilience Alliance

The following is the established format for referencing this article:

Jonsen, I. and P. D. Taylor. 2000. Calopteryx damselfly dispersions arising from multiscale responses to landscape structure. Conservation Ecology 4(2): 4. [online] URL: http://www.consecol.org/vol4/iss2/art4/

A version of this article in which text, figures, tables, and appendices are separate files may be found by following this link.

Report

\title{
Calopteryx Damselfly Dispersions Arising from Multiscale Responses to Landscape Structure
}

\author{
Ian Jonsen and Philip D. Taylor
}

\section{Acadia University}

- Abstract

- Introduction

- Methods

- Study landscapes

- Field surveys

- Simulation models

Model evaluation

Simulation experiment

- Results

- Field surveys

- Model evaluation

- Simulation experiment

- Discussion

- Empirical distributions

- Simulations

- Speculation

- Responses to this Article

- Acknowledgments

- Literature Cited

- Appendix 1

- Appendix 2

- Appendix 3

- Appendix 4

- Erratum (added 4 J anuary 2001)

\begin{abstract}
Using spatially explicit simulation models, we explored the extent to which fine-scale (i.e., meters to tens of meters) movement behaviors could be used to predict broader scale patterns of distribution on heterogeneous landscapes. Our models were tailored by empirical data on Calopterygid damselfly movements on three types of landscapes that differed in amount of forest habitat. Surveys of the two congeneric damselflies, Calopteryx aequabilis and Calopteryx maculata, demonstrated that both species occupied stream
\end{abstract}


and forest habitats on forested and partially forested landscapes, but were found primarily along streams on nonforested landscapes. Simulation models whose parameters were derived using empirical movement data for both species showed that fine-scale movement behaviors could be used to predict, on average, broader scale dispersion across a range of landscape structures, but that it was necessary to include information about broader scale landscape features in those models. In particular, the probability of crossing a patch boundary ( patch boundary permeability) and the rate of movement in a given habitat patch (patch viscosity) were important determinants of damselfly dispersion on heterogeneous landscapes. In other words, our results suggest that damselfly dispersions may arise as a function of behavioral responses to spatial patterns at multiple scales.

KEY WORDS: Calopteryx aequabilis, Calopteryx maculata, connectivity, damselflies, landscape structure, movement behaviors, multiscale dispersion, patch boundary permeability, patch viscosity, simulation model, spatial scale.

Published: October 3, 2000

\section{NTRODUCTI ON}

Exploring how animals move in response to the spatial structure of their environment is a critical step toward understanding the processes that determine spatial distributions and population dynamics. Various studies indicate that movement plays an important role in the spatial distribution and dynamics of many animal populations (Fahrig and Merriam 1985, Kareiva 1987, Fahrig and Paloheimo 1988, Turchin 1991, Hanski 1994, Lele et al. 1998, Moilanen and Hanski 1998). At an individual level, the spatial and temporal scales of animal-heterogeneity interactions are dictated largely by an animal's movement behavior (Wiens and Milne 1989, With et al. 1997) and perceptual ability (With 1994a, Lima and Zollner 1996, Zollner and Lima 1997). Individual differences in movement behavior and/or perceptual ability may help determine whether or not populations persist when faced with the types of changes in spatial structure (e.g., Roitberg and Mangel 1997) that arise from habitat loss or fragmentation.

The ability of an animal to move through a landscape is referred to as "functional connectivity" (With et al. 1999). The composition of habitats on a landscape, their spatial configuration, and the movement behavior of the animal are critical components of functional connectivity (Taylor et al. 1993, With et al. 1999).

Functional connectivity can be summarized by two components of the interaction between animal movement and spatial structure: (1) "patch viscosity" (With 1994b, Wiens et al. 1997), or the rate at which an animal moves through a given habitat patch, and (2) "patch boundary permeability" (Stamps et al. 1987, Wiens 1997, Wiens et al. 1997, Jonsen and Taylor 2000), which is the probability that an animal will cross a boundary between two different habitats. Although both these concepts are by definition patch-based, recent empirical work (Wiens et al. 1997, J onsen and Taylor 2000) indicates that both within-patch rates of movement and decisions to cross patch boundaries are affected by the total amount of suitable habitat on the landscape (i.e., "patch context" as defined by Wiens et al. 1997). This suggests that there is a multiscale component to both patch viscosity and patch boundary permeability. In other words, for at least some animals, fine-scale movements arise from responses both to internal patch characteristics and to broader scale landscape characteristics.

In this study, we compared the spatiotemporal distributions between stream and forest habitats of two species of Calopterygid damselfly (Odonata:Calopterygidae), Calopteryx aequabilis Say and C. maculata (P. de Beauvois) (Appendix 1), on three types of landscapes that differed in amount of forest habitat. Both species require streams for naiad development and breeding, and often forage in forests. Although both species are nominally forest damselflies, we have observed them occupying streams on landscapes ranging from complete to little or no forest cover. Males defend oviposition sites along streams (Johnson 1962, Waage 1972) and mate with females at these sites (but see Forsyth and Montgomerie 1987). These breeding (streams) and foraging (forest) habitats are thus important focal resources, and both sexes of both species are capable of flying between stream and forest patches at least $700 \mathrm{~m}$ apart (Pither and Taylor 1998).

Focusing strictly on patterns of distribution among stream and forest habitats, we derived two individualbased, spatially explicit simulation models from empirical observations of damselfly movements (J onsen and Taylor 2000). We used these models to explore the extent to which C. aequabilis and C. maculata dispersions on heterogeneous landscapes arose as the aggregate of individual fine-scale (i.e., meters to tens of meters) movement behaviors, and to determine the extent to which a broader scale feature of these landscapes (amount of forest habitat) may influence observed patterns of dispersion. Our simulation approach was analogous to those of other individual-based simulations that have explored the interactions between spatial structure and animal movement (e.g., Odendaal et al. 1989, Johnson et al. 1992, With and Crist 1995 , 1996, Gustafson and Gardner 1996, Schippers et al. 1996, Schumaker 1996, With et al. 1997). We built on the modeling approaches used in these studies by conducting simulations of damselfly movement on digitized representations of real landscapes, using empirically observed movement data and testing model predictions with empirically observed distribution data. 
The patterns of distribution we explored were not broad-scale equilibrium patterns of population distribution but rather meso-scale (i.e., landscape-scale, here $1 \mathrm{~km}^{2}$ in extent), daily distributions of damselflies on landscapes that differed in amount of forest habitat. Although not an explicit test of the link between individual movements and population distribution, our study nevertheless explored the interaction between finescale movement and spatial structure and its effect on broader scale distribution.

\section{METHODS}

\section{Study landscapes}

Our study was conducted in the Annapolis Valley region (45으오 N, 64ㅇ 30' W) of Nova Scotia, Canada, from J une to August 1996 (Fig. 1). Throughout the region, populations of both species occur along streams that flow through forest and also through agricultural land (mainly pasture). In some areas, anthropogenic activity has altered the landscape by replacing forest with novel habitat (e.g., the light-colored urban and farmland areas in Fig. 1). On landscapes dominated by forest, damselflies need not move far to access resources, because stream and forest habitats abut. On partially forested landscapes, patches of pasture separate stream and forest; on predominantly unforested landscapes, there is little or no forest available within the typical ecological neighborhoods (sensu Addicott et al. 1987) of foraging damselflies, i.e., about 500-750 m away from streams (Taylor and Merriam 1995, Pither and Taylor 1998). Thus, the composition and configuration (sensu Taylor et al. 1993) of forested, partially forested, and unforested landscapes differ.

Fig. 1. False-color satellite image of the study region (Annapolis Valley, Nova Scotia, Canada). The forested North and South Mountains (medium and light green) bound the agricultural valley (diagonal band of white, pink, and light green). Water bodies are black. The 15 landscapes used in this study are indicated by yellow (forested), blue (partially forested), and red (nonforested) circles. All 15 landscapes were used for surveys, and six (opaque circles), two in each level of forest cover, were used to collect movement data (Jonsen and Taylor 2000). Three landscapes (indicated by double circles), one in each level of forest cover, were used for model calibrations, and the remaining 12 were reserved to test model predictions.

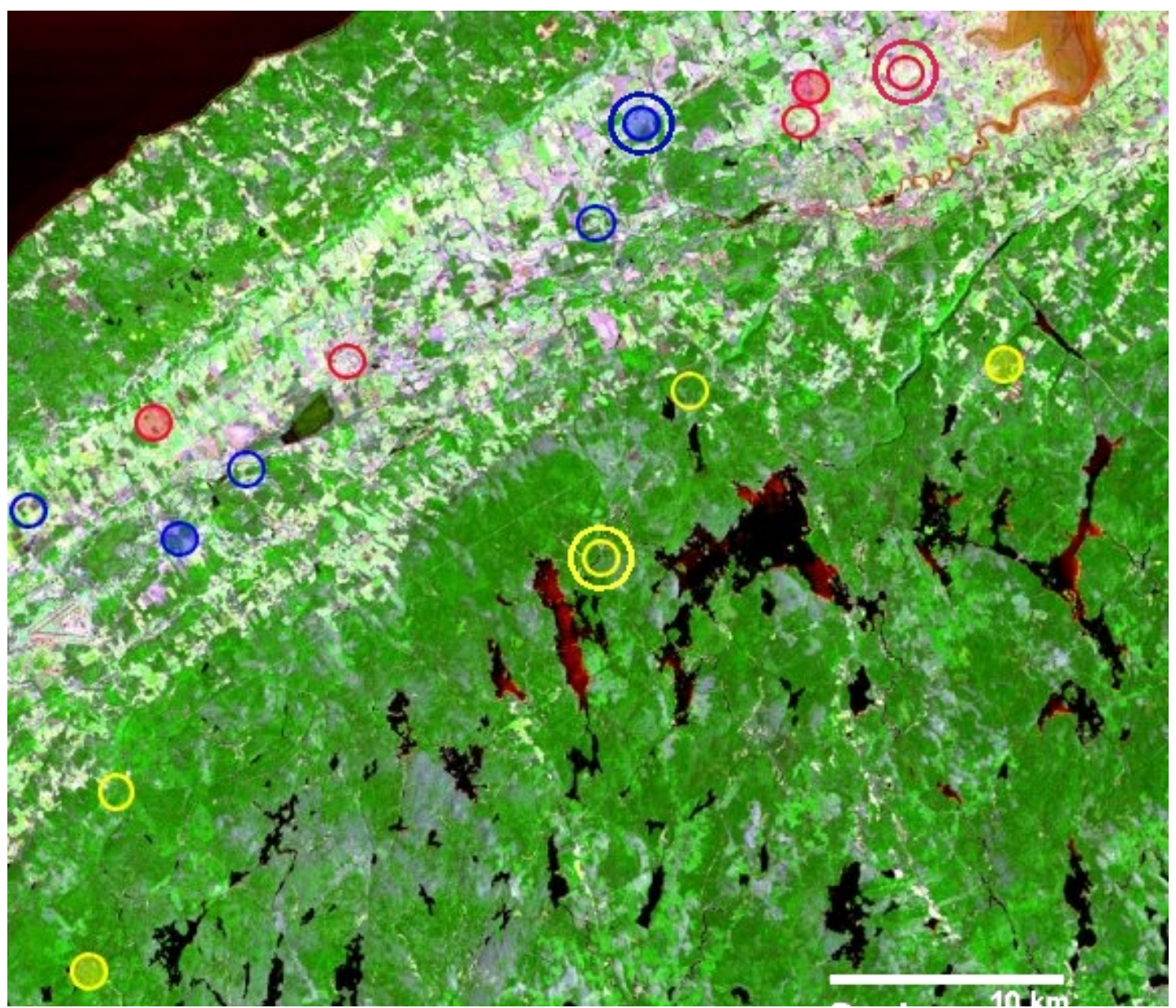




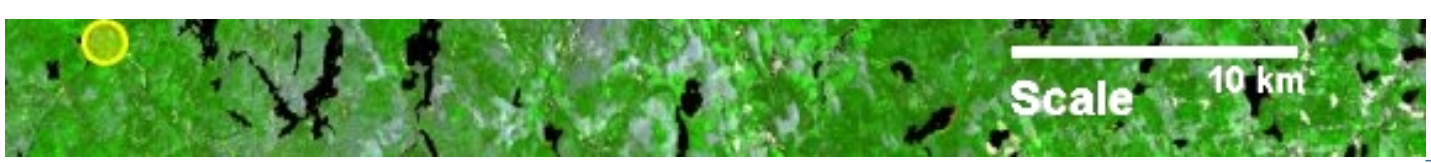

We categorized the landscapes according to the proportion of forest within $500 \mathrm{~m}$ of streams using aerial photos (on a scale of 1:10,000) from the Nova Scotia Department of Natural Resources. Forested landscapes (FO) were deemed to consist of a stream flowing directly through continuous forest (the proportion of forest was 0.79 \pm 0.04 , mean \pm 1 SD) (Fig. 2). Partially forested landscapes (PF) were those in which streams flow through pasture with moderate to large forest patches $50-500 \mathrm{~m}$ distant (the proportion of forest was $0.38 \pm 0.09$, mean \pm 1 SD) (Fig. 2). On nonforested landscapes (NF), streams flow through pasture with only a few small forest patches or, in one case, no forest at all within $500 \mathrm{~m}$ of the stream (the proportion of forest was $0.10 \pm 0.03$, mean \pm 1 SD) (Fig. 2). Throughout this study, we refer to pasture as any nonforested, grassy, or crop habitat. In total, 15 landscapes were surveyed, five in each landscape category. For simulations, landscapes were digitized from aerial photos (on a scale of $1: 10,000$ ) at a resolution of $2 \mathrm{~m} /$ pixel, with an extent of $1000 \mathrm{~m}(0 \mathrm{r}$ 500 pixels) on each side, and were roughly centered on the portion of stream habitat used in empirical surveys (see Field surveys).

Fig. 2. Examples of digitized landscapes in each landscape category. Note that all nonhabitat components are represented by pasture habitat (see Study landscapes). Digitized landscape dimensions are $500 \times 500$ pixels, representing $1000 \times 1000$ m, i.e., each pixel represents $2 \mathrm{~m}$ on a side.

Forested

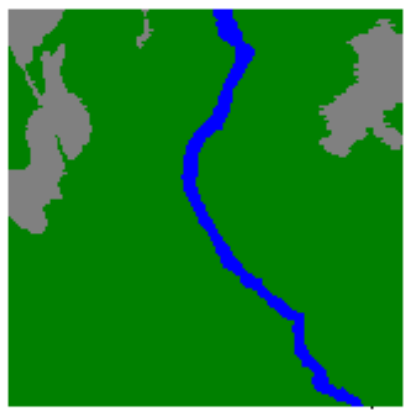

Partially forested

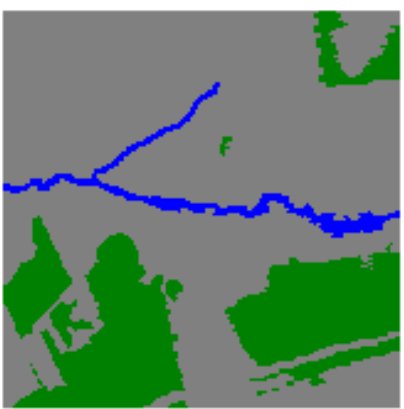

Nonforested

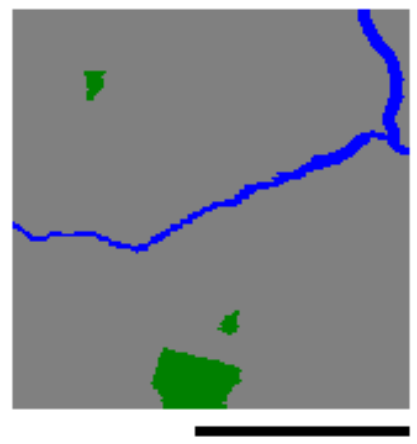

Stream

Pasture

Forest 
We sampled Calopteryx aequabilis and Calopteryx maculata populations on $120 \times 10 \mathrm{~m}$ transects at streams and on $200 \times 10 \mathrm{~m}$ transects in forest (50-500 m from the stream). We were not able to walk forest transects at the same distance from streams on all landscapes because of the unique dispersion of forest patches on each landscape. Each landscape was sampled by timed counts of damselflies present along stream and forest transects. All damselflies found along transects were identified and SEXed; the two species are easily distinguished and sexed at distances of up to about $10 \mathrm{~m}$. (As in the preceding sentence, factors included in statistical models are presented in a SMALL CAPS font.) Transects in each RESOURCE (stream and forest) were walked at two of five different TIMEs of day on each individual LANDSCAPE in each of the MONTHs of J uly and August. Therefore, each LANDSCAPE category had two replicate LANDSCAPEs surveyed at each of the five TIMEs of day. The survey design was completely balanced by transect for these additional factors: LANDSCAPE, RESOURCE, TIME, and MONTH.

We fit a log-linear model, i.e., a generalized linear model with Poisson errors (McCullagh and Neldar 1989), to damselfly counts. We modeled the effects of LANDSCAPE type, RESOURCE type, TIME of day, and SEX on the counts of $C$. aequabilis and $C$. maculata observed along the transects. The TIME and MONTH factors were both coded as ordinal factors. We fit MONTH to control for differences in counts of both species observed in July and August. For all statistical models, we set maximum Type I error rates to $W=0.10$ and assessed effects according to biological importance.

\section{Simulation models}

Our simulations explored the extent to which landscape-scale dispersion was influenced by (1) patch viscosity and patch boundary permeability and (2) a broader scale feature of the landscape: amount of forest cover. Using empirical data from our damselfly system, we modeled patch viscosity as habitat-specific move lengths and turn angles and patch boundary permeability as the probability of moving away from streams. Our models were very simple, using only the bare minimum of parameters to predict patterns of distribution and ignoring many of the details of Calopteryx biology. We focused explicitly on previously observed interactions between fine-scale movement behavior and landscape structure (Jonsen and Taylor 2000), which enabled us to construct our models from parameters based on empirical data rather than educated guesses.

We developed two models that were variations on a correlated random walk (CRW) process (Turchin 1998) with spatially varying movement parameters (e.g., Turchin 1991). To correspond closely to our empirical data, movements in these models were vector- rather than cell-based (see Appendix 2 and Appendix 4). By incorporating patch viscosity and patch boundary permeability in an iterative fashion, these models addressed our overall goal of determining the extent to which interactions between fine-scale movements and landscape structures translated into broader scale dispersion. We began with a simple model (VISCOSITY), in which movements were described by habitat-specific move lengths $(M)$ and turn angles $(T)$ that were drawn at random from empirically observed distributions for each habitat type. We used this model to determine if damselfly dispersions on heterogeneous landscapes arose solely as a function of spatial variation in movement rates (i.e., variation in patch viscosity among different habitat types). We then tested a more complex model (PERMEABILITY) that incorporated a patch boundary permeability parameter into the VISCOSITY framework. We used this second model to determine if it was necessary to include information about responses to patch boundaries to predict damselfly dispersions. See Appendix 3 for a summary of the features of each model and Appendix 2 and Appendix 4 for a more detailed explanation of model components.

To further assess the effect of the interaction between movement and landscape structure on dispersion, we used different distributions of move lengths and probabilities of crossing a stream boundary for models run on each of the three landscape types. We show elsewhere (Jonsen and Taylor 2000) that the probabilities of crossing a stream boundary differ significantly among landscape types. Move length distributions for both species were significantly different among stream, pasture, and forest habitats, but were different only on FO landscapes when only stream move lengths on different landscape types were compared (Fig. 3). Turnangle distributions did not differ significantly among habitat types for either species, although circular histograms (Fig. 4) suggest that C. aequabilis reverses direction far more often in stream habitat than in forest or pasture. We varied the parameters related to move length and the probability of crossing a stream boundary among landscape types to determine if landscape-level distributions arose as the aggregate of finescale movement responses to (1) the various configurations of stream, pasture, and forest habitats on landscapes, or (2) the various configurations of stream, pasture, and forest and the amount of forest habitat present on the different landscapes. We reasoned that, if landscape-level distributions arise simply as the aggregate of finescale movement responses to the habitat types present and their unique spatial configurations among landscapes, then a simple model in which movement parameters vary among habitat types but not among landscape types should suffice. However, if damselflies also respond to the amount of suitable habitat present on a landscape, then a model that accounts for differences in fine-scale movements among different habitat types and among different landscape types may be required to predict dispersions adequately. 
Fig. 3. Box plots of nonzero move length distributions for Calopteryx aequabilis and Calopteryx maculata observed in each habitat type (top row) and for stream move lengths observed on each landscape type (bottom row). The plots display the median value (white bar), interquartile range (box), range (whiskers), and outliers (empty circles). Numbers near the tops of panels indicate the number of $0-\mathrm{m}$ move lengths for stream distributions. Relative sample sizes of nonzero move lengths are indicated by the width of the boxes. Boxes labeled with different letters are significantly different at a $=0.10$ (Wilcoxon rank-sum tests). The abbreviations FO, PF, and NF stand for "forested," "partially forested," and "nonforested," respectively.
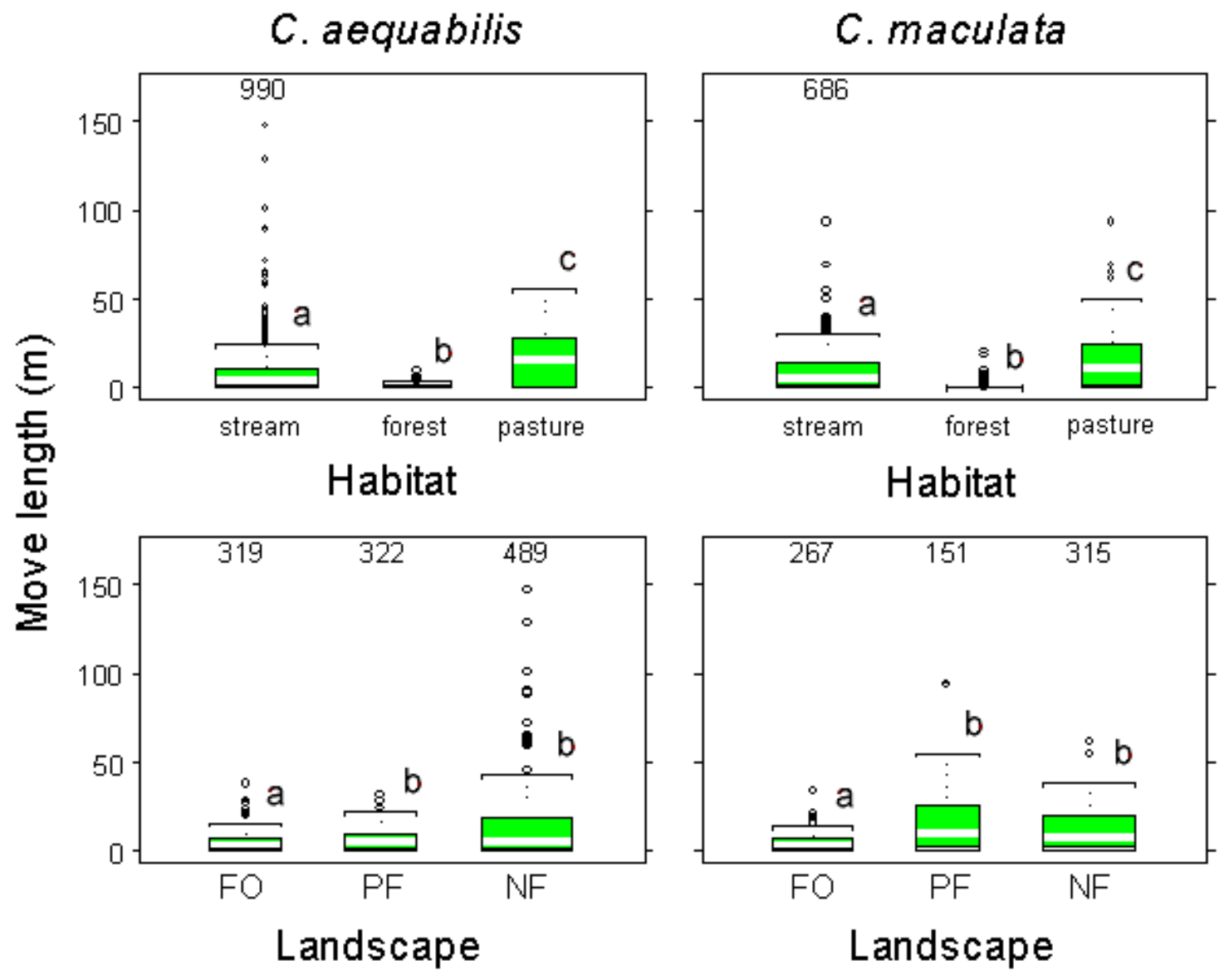

Fig. 4. Circular histograms of turn-angle distributions for Calopteryx aequabilis and Calopteryx maculata observed in each habitat type. Note the different scales along the internal axes (frequency) among species and habitat type. We observed a greater number of turns in stream habitat than in either forest or pasture (see Methods). Kruskal-Wallis rank-sum tests did not detect any significant turn-angle differences among the three habitats for either species. 


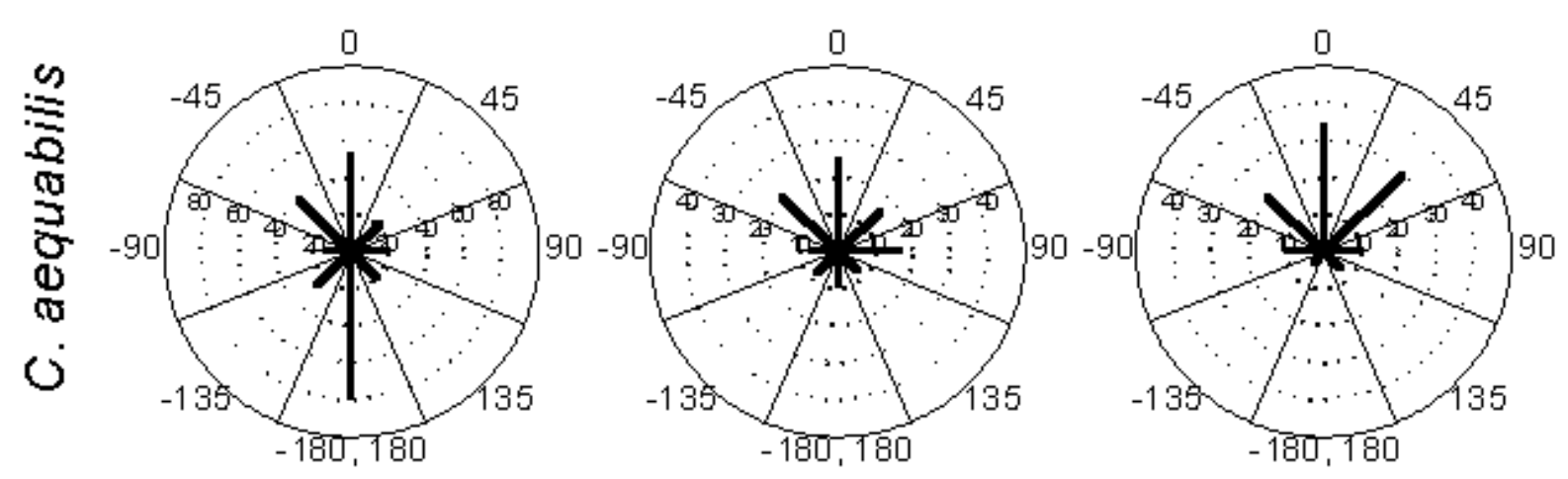

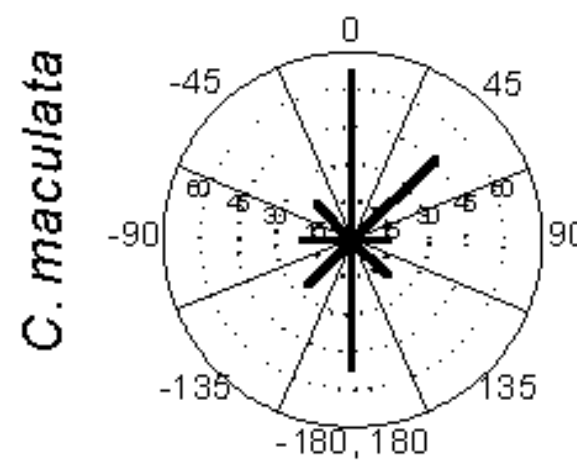

stream

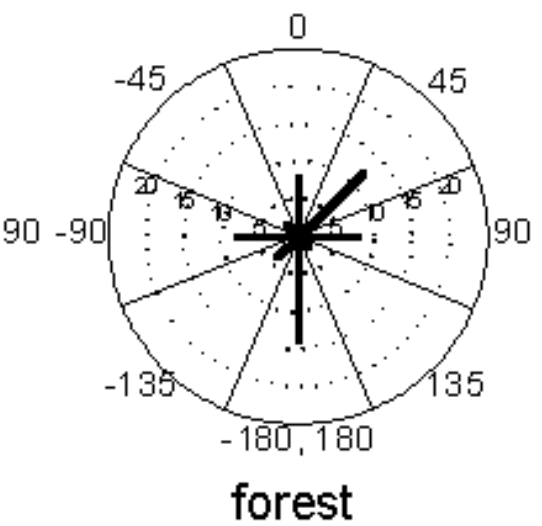

forest

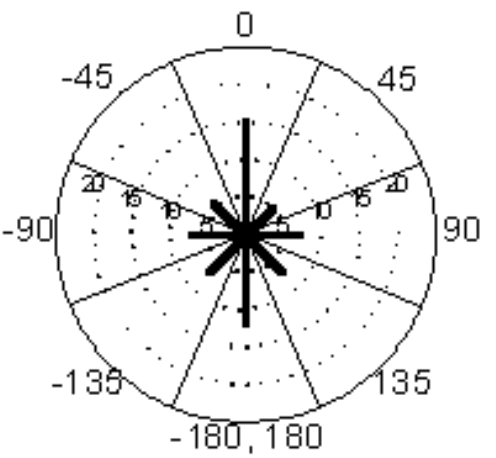

pasture

\section{Habitat}

We varied movement parameters by separating probabilities of crossing stream boundaries $\left(P_{m v}\right)$ and stream move length distributions ( $\mathrm{M}_{\text {stm }}$ ) according to landscape type. We had sufficient movement observations to separate move lengths and turn angles into habitat-specific distributions. However, because of limitations in our ability to track damselflies (see Jonsen and Taylor 2000), we did not have enough observations to further separate move lengths in pasture and forest or turn angles in all three habitats into landscapespecific distributions. Thus, for the VISCOSITY model, we used two parameter sets: (1) "Basic," in which M stm is invariant among landscape types, and (2) "M stm" in which $\mathrm{M}_{\text {stm }}$ varies among landscape types. For the PERMEABILITY model, we used four parameter sets: (1) Basic, in which $\mathrm{M}_{\text {stm }}$ and $\mathrm{P}_{\mathrm{mv}}$ are invariant among landscape types; (2) "P $\mathrm{mv}^{\prime}$ " in which $\mathrm{P}_{\mathrm{mv}}$ varies among landscape types, but $\mathrm{M}_{\text {stm }}$ does not; (3) "M ${ }_{\text {stm'" }}$ in which $M_{\text {stm }}$ varies among landscape types, but $P_{m v}$ does not; and (4) "Both," in which both $P_{m v}$ and $M_{\text {stm }}$ vary among landscape types (see $\underline{\text { Appendix } 2}$ and $\underline{\text { Appendix } 3 \text { ). }}$.

\section{Model evaluation}

The ability of the models to predict the proportions of each species in stream and forest habitats was evaluated by running each model 10 times for each parameter set on each of the digitized landscapes. We randomly selected three landscapes (one in each category) for model calibrations and reserved the remaining 12 for model evaluation. In total, 120 simulations were conducted for each parameter set: 240 runs for the VISCOSITY model (two parameter sets) and 480 runs for the PERMEABILITY model (four parameter sets). 
We tested model predictions by calculating the percentage of error of each combination of model and parameter set when these were fit to observed proportions of damselflies along streams and in forest on each landscape. We set a cutoff value of $\pm 25 \%$ error; values within this range represent good agreement between simulated and observed data as per Turchin (1991). For brevity, we compared only predicted vs. observed results for stream habitat, because the proportion of damselflies occupying forest habitat was equal to one minus the proportion occupying stream habitat.

\section{Simulation experiment}

Focusing on C. maculata, we conducted a factorial experiment to determine how the model's ability to predict observed dispersions among different landscape types was affected by (1) increases in movement rates $\left(\mathrm{M}_{\text {pas }}\right.$ ) and persistence of direction ( $\mathrm{T}_{\text {pas }}$ ) in nonhabitat (pasture) relative to those in stream ( $\mathrm{M}_{\text {stm' }}$ $T_{\text {stm }}$ ) and forest ( $M_{\text {for }}, T_{\text {for }}$ ) habitats and (2) increases in patch boundary permeability $\left(P_{m v}\right)$. In other words, we wanted to know how sensitive model predictions were to these two components of movement. To reduce the complexity of the experiment, we did not vary the $\mathrm{M}$ and $\mathrm{T}$ parameters independently in forest and pasture habitats. We used three levels of $M$ and $T$ and four levels of $P_{m v}$ (see Table 1 ). We varied move length distributions in stream habitat $\left(\mathrm{M}_{\mathrm{stm}}\right)$ and $\mathrm{P}_{\mathrm{mv}}$ (first level only) among landscape types, whereas all distributions of turn angle and move length in forest $\left(\mathrm{M}_{\text {for' }} \mathrm{T}_{\text {for }}\right)$ and pasture $\left(\mathrm{M}_{\text {pas' }} \mathrm{T}_{\text {pas }}\right)$ habitats and the remaining three levels of $\mathrm{P}_{\mathrm{mv}}$ were held constant among landscape types (Table 1 ). Move lengths

were generated from exponential distributions (Mathsoft 1999), and turn angles from circular-normal distributions (Batschelet 1980). We graphically assessed the ability of the PERMEABILITY model to predict observed proportions of $\mathrm{C}$. maculata across the three landscape types for all combinations of the $\mathrm{M}$, $\mathrm{T}$, and $\mathrm{P}_{\mathrm{mv}}$ parameters. In all cases, we tested model predictions using our empirical distribution data.

Table 1. Parameter values used in the simulation experiment. Move length values $\left(M_{s t m}, M_{f o r}, M_{\text {pas }}\right.$ ) are mean distances (in meters) from exponential distributions. Turn-angle values are concentration parameters ( $T_{\text {stm }}$ ' $T_{\text {for' }} T_{\text {pas }}$ ) from circular-normal distributions with means $=0 . P_{m v}$ values are probabilities of individual damselflies moving away from streams in a single time step. Simulations were run with each combination of $M, T$, and $P_{m v}$. To reduce complexity, the $M$ and $T$ parameters were not varied independently. Level refers to the different parameter values used in the experiments (three for $\mathrm{M}$ and $\mathrm{T}$ and four for $\mathrm{P}_{\mathrm{mv}}$ ). Level-2 $\mathrm{M}$ and $\mathrm{T}$ parameters approximate observed values for each habitat type. Level-1 $\mathrm{P}_{\mathrm{mv}}$ parameters are the observed values for each landscape type: forested (FO), partially forested (PF), and nonforested (NF).

\begin{tabular}{|c|c|c|c|c|c|c|c|c|c|c|c|}
\hline & \multicolumn{4}{|c|}{ Stream } & \multicolumn{2}{|c|}{ Forest } & \multicolumn{2}{|c|}{ Pasture } & & & \\
\hline & \multicolumn{3}{|c|}{$M_{\text {stm }}$} & \multirow[t]{2}{*}{$\mathrm{T}_{\mathrm{stm}}$} & \multirow[t]{2}{*}{$M_{\text {for }}$} & \multirow[t]{2}{*}{$T_{\text {for }}$} & \multirow[t]{2}{*}{$M_{\text {pas }}$} & \multirow[t]{2}{*}{$\mathrm{T}_{\text {pas }}$} & \multicolumn{3}{|c|}{$P_{m v}$} \\
\hline Level & FO & PF & NF & & & & & & FO & PF & NF \\
\hline 1 & 1 & 2 & 2 & 0.1 & 0.5 & 0.1 & 2 & 0.1 & 0.017 & 0.013 & 0.005 \\
\hline 2 & 2 & 5 & 3 & 0.2 & 1 & 0.2 & 20 & 1 & 0.05 & 0.05 & 0.05 \\
\hline 3 & 5 & 8 & 6 & 1 & 3 & 1 & 75 & 5 & 0.1 & 0.1 & 0.1 \\
\hline 4 & $\ldots$ & $\ldots$ & $\ldots$ & $\ldots$ & $\ldots$ & $\ldots$ & $\ldots$ & $\ldots$ & 0.5 & 0.5 & 0.5 \\
\hline
\end{tabular}

\section{RESULTS}

\section{Field surveys}

We observed 338 Calopteryx aequabilis (147 females, 191 males) and 289 Calopteryx maculata (126 females, 
163 males) along transects. On counts of both species, the models showed significant interactions between the following pairs of factors: RESOURCE and SEX, RESOURCE and TIME, LANDSCAPE and TIME, and LANDSCAPE and RESOURCE (the boldface interaction terms in the first column of Table 2).

Table 2. Analysis of deviance table. The response variables are the counts of Calopteryx aequabilis and Calopteryx maculata observed along transects. The models are log-linear models fit with a log link and Poisson errors. In the first column, significant interaction terms are written in boldface. $\mathrm{P}$ values are based on tests against $X^{2}$ distributions. Trends among levels of factors in significant interactions are displayed in Fig. 5.

\begin{tabular}{|c|c|c|c|c|c|}
\hline & & \multicolumn{2}{|c|}{ C. aequabilis } & \multicolumn{2}{|c|}{ C. maculata } \\
\hline Term & df & Deviance & $P$ & Deviance & $P$ \\
\hline Null & 239 & 730.98 & & 666.18 & \\
\hline MONTH & 1 & 7.74 & 0.005 & 8.12 & 0.004 \\
\hline SEX & 1 & 5.27 & 0.022 & 4.42 & 0.035 \\
\hline TIME & 4 & 37.56 & $<0.001$ & 63.79 & $<0.001$ \\
\hline RESOURCE & 1 & 274.52 & $<0.001$ & 142.70 & $<0.001$ \\
\hline LANDSCAPE & 2 & 81.73 & $<0.001$ & 102.22 & $<0.001$ \\
\hline TIME $\times$ SEX & 4 & 3.99 & 0.408 & 1.56 & 0.817 \\
\hline RESOURCE X SEX & 1 & 6.47 & 0.011 & 8.17 & 0.004 \\
\hline RESOURCE X TI ME & 4 & 23.57 & $<0.001$ & 51.98 & $<0.001$ \\
\hline LANDSCAPE $\times$ SEX & 2 & 3.45 & 0.178 & 1.89 & 0.388 \\
\hline LANDSCAPE $\times$ TI ME & 8 & 31.56 & $<0.001$ & 14.60 & 0.068 \\
\hline LANDSCAPE x RESOURCE & 2 & 32.24 & $<0.001$ & 42.92 & $<0.001$ \\
\hline RESOURCE $\times$ TIME $\times$ SEX & 4 & 5.97 & 0.202 & 6.83 & 0.145 \\
\hline LANDSCAPE x TIME x SEX & 8 & 3.38 & 0.909 & 4.06 & 0.852 \\
\hline LANDSCAPE $\times$ RESOURCE $\times$ SEX & 2 & 4.10 & 0.129 & 0.02 & 0.988 \\
\hline LANDSCAPE $\times$ RESOURCE $\times$ TIME & 8 & 10.23 & 0.249 & 4.41 & 0.818 \\
\hline $\begin{array}{l}\text { LANDSCAPE } \times \text { RESOURCE } \times \text { TIME } \times \\
\text { SEX }\end{array}$ & 8 & 1.67 & 0.989 & 2.93 & 0.939 \\
\hline Residual & 179 & 197.54 & & 205.56 & \\
\hline
\end{tabular}

Both species were consistently more abundant along streams than in forest, but this relationship between focal RESOURCEs was modified by interactions with SEX and TIME of day (Table 2). Males were more abundant along streams, and females were slightly more abundant in forest (RESOURCE x SEX in Table 2 and Fig. 5, A and E). This pattern was consistent across forested (FO) and partially forested (PF) landscapes (no LANDSCAPE x RESOURCE x SEX interaction in Table 2), but on nonforested (NF) landscapes only a single damselfly was ever found in forest (as previously stated, NF landscapes can contain a small amount of forest cover). Both species were generally most abundant in forest early (0700-0900) and late (1700-1900) in the day, which was also when they were least abundant along streams (RESOURCE x TIME in Table 2 and Fig. 5 , B and $F$ ). This pattern was consistent among LANDSCAPEs (no LANDSCAPE $x$ RESOURCE x TIME interaction in Table 2). 
Fig. 5. Interaction plots of the mean counts of $(A)$ Calopteryx aequabilis and $(E)$ Calopteryx maculata in forest and stream resources, according to sex; (B) C. aequabilis and (F) C. maculata at different times of day, according to resource type; (C) C. aequabilis and $(G) C$. maculata at different times of day, according to landscape type; and (D) C. aequabilis and (H) C. maculata on forested (FO), partially forested (PF), and nonforested (NF) landscapes, according to resource type. Points indicate observed mean counts. Time periods are: I, 0700-0900; II, 0900-1100; III, 1100-1400; IV, 1400-1700; V, 1700-1900.

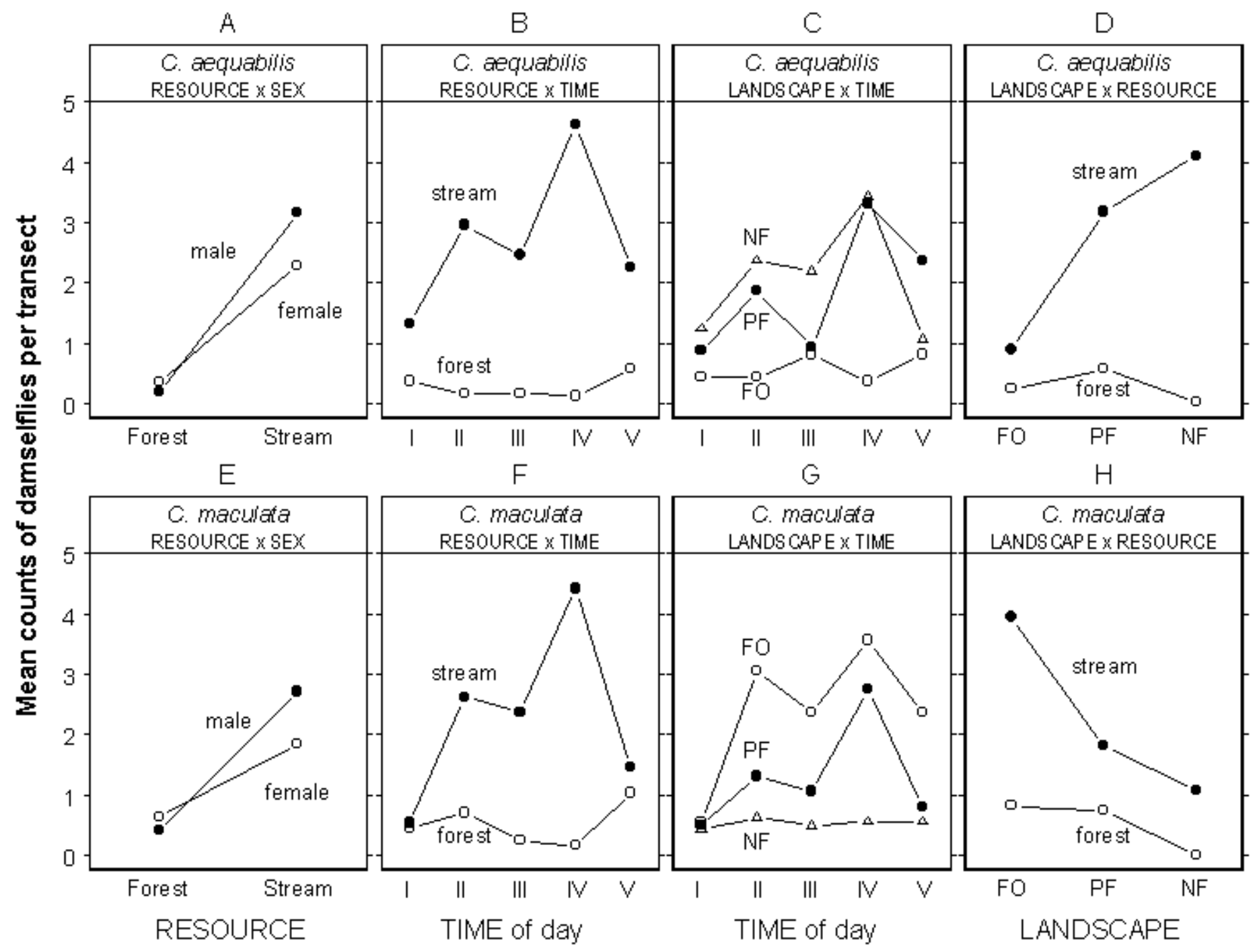

There was a distinct difference in the distribution of the two species among LANDSCAPEs. Both species had similar patterns of abundance throughout the day, but $\mathrm{C}$. aequabilis was most abundant on NF and PF LANDSCAPEs, while C. maculata was most abundant on FO and PF LANDSCAPEs (Fig. 5 , C and G). This pattern was more evident in the pattern of RESOURCE use on different landscapes (Fig. 5, D and H). Despite their preferences for opposite types of landscape structures, both species had similar patterns of RESOURCE use among the different LANDSCAPEs in that both were found along streams and in forest on FO and PF LANDSCAPEs, but neither tended to be found in forest on NF LANDSCAPEs (Fig. 5, D and H).

\section{Model evaluation}

The VISCOSITY model failed to predict observed patterns of distribution between stream and forest habitat on any landscape type (the Basic and $\mathrm{M}_{\text {stm }}$ parameter sets for the VISCOSITY model in Fig. 6). Although accounting 
for the effect of landscape structure on rates of movement in stream habitat improved model predictions slightly (compare percentage of error values between Basic and $M_{\text {stm }}$ parameter sets in the VISCOSITY model in

Fig. 6), the mean percentage of error between predicted and observed proportions of damselflies in stream habitat exceeded $50 \%$ (in a negative direction) for both species. The VISCOSITY model consistently predicted that more damselflies would move away from streams than were observed based on our survey data.

Fig. 6. Interaction plots of the percent error of the VISCOSITY and PERMEABILITY models (all parameter sets) fit to observed proportions of Calopteryx aequabilis and Calopteryx maculata along stream habitat, according to landscape type: forested (FO), partially forested (PF), and nonforested (NF). The parameter sets used for the two models are represented by the labels on the $x$-axis. For both models, the parameter sets differ with regard to the probability of moving off stream and/or variations in stream move lengths among landscape types: Basic, parameters are invariant among landscape types; $\mathrm{M}_{\text {stm }}$, stream move length distributions vary among landscape types; $\mathrm{P}_{\mathrm{mv}}$, probabilities

of moving off stream vary among landscape types; Both, both stream move length distributions and probabilities of moving off stream vary among landscape types. Data points are mean percentage of error ([predicted - observed]/observed x 100) of proportion of damselflies along streams, based on 40 simulation runs per landscape type (10 per individual landscape). The horizontal dotted line indicates perfect agreement between predicted and observed data. The horizontal dashed lines indicate the $\pm 25 \%$ cutoff between acceptable and poor model fit. Within- and among-landscape variation in model fits, best-fitting model(s) only, are presented in Fig. 7 (C. aequabilis) and Fig. 8 (C. maculata).

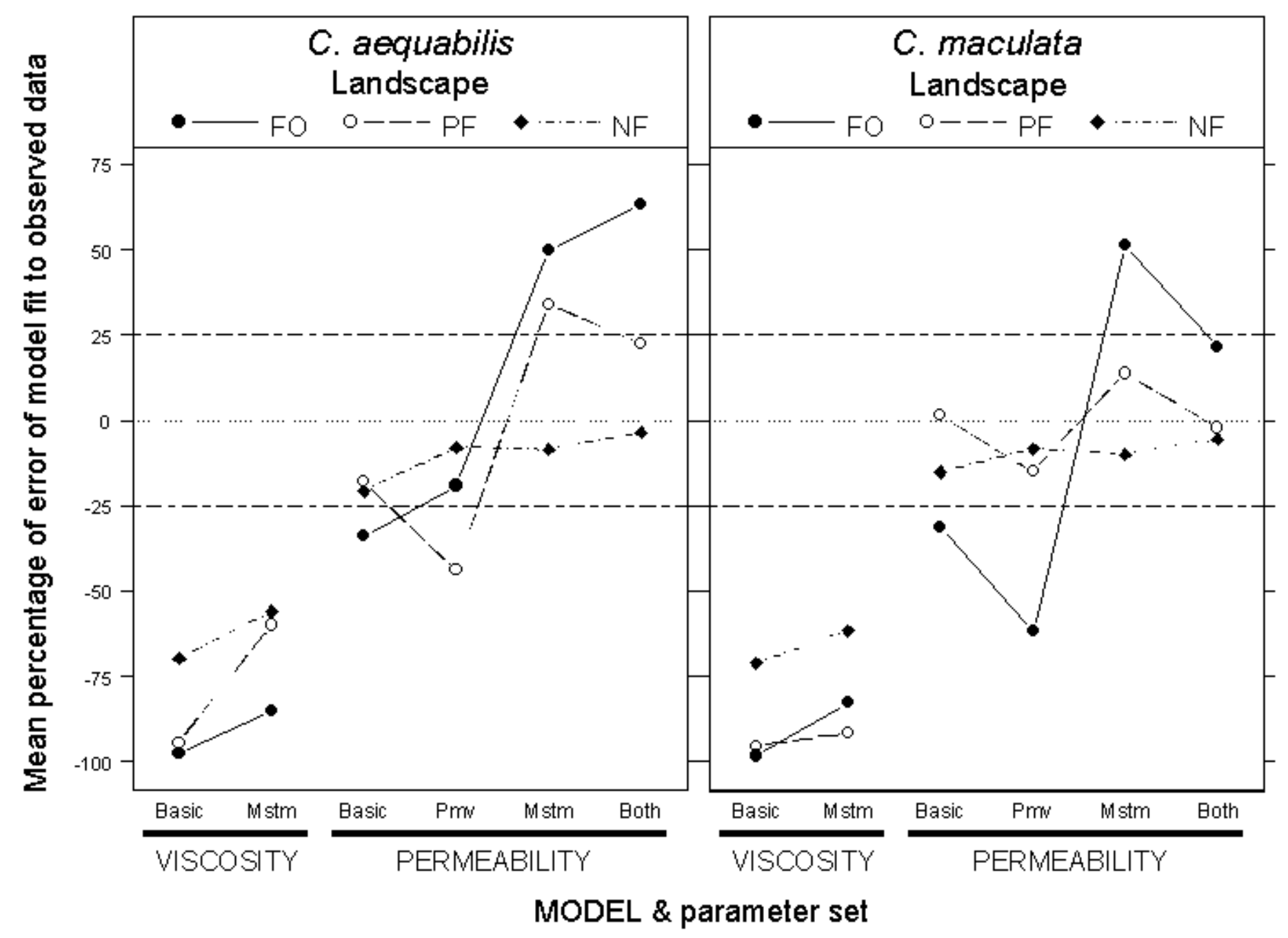


The addition of a stream boundary behavior to the PERMEABILITY model was, in most cases, a clear improvement over the VISCOSITY model (Fig. 6). However, accounting for effects of landscape structure on movement behavior produced mixed results for both species. For $\mathrm{C}$. aequabilis, the Basic and $\mathrm{P}_{\mathrm{mv}}$ parameter sets generated the model fit with the lowest percentage of error across all three landscapes types (the absolute value of percentage of error pooled among landscape types: $35.4 \pm 18.1 \%$, mean \pm 1 SD for Basic; $27.2 \pm$ 24.4\%, mean \pm 1 SD for $P_{m v}$ ). The Basic parameter set generated adequate predictions on PF and NF landscapes, but not on FO landscapes, whereas the $\mathrm{P}_{\mathrm{mv}}$ parameter set generated adequate predictions on FO and NF landscapes, but not on PF landscapes (Fig. 6). An examination of the variability in the percentage of error of model fit among replicate landscapes within a category indicated that the $\mathrm{P}_{\mathrm{mv}}$ parameter set was a better fit

to the observed data on FO and NF landscapes than was the Basic parameter set: model predictions on a greater number of replicate landscapes fell within the $\pm 25 \%$ range for the $P_{m v}$ parameter set (Fig. 7 ).

However, neither the Basic nor the $\mathrm{P}_{\mathrm{mv}}$ parameter set adequately predicted damselfly distributions on PF landscapes, where model predictions on one replicate were vastly different from those on the other three replicates (top and bottom panels in the center of Fig. 7).

Fig. 7. Box plots displaying the percentage of error between predicted and observed proportions of Calopteryx aequabilis along stream habitat on individual landscapes, for the Basic and $\mathrm{P}_{\mathrm{mv}}$ parameter

sets of the PERMEABILITY model. Individual boxes represent among-run variation in model fits on individual landscapes. Total variation among individual landscapes within a landscape type is represented by the blue box (Total) in each panel. The numbers along the $x$-axes are individual landscape designations. The plots display the median value (white bar), mean value (yellow diamond), interquartile range (box), range (whiskers), and outliers (bars). Yellow diamonds, blue boxes only, display mean percentage of error for comparison with Fig. 6 . The horizontal dotted line through each panel indicates perfect agreement between predicted and observed data. Dashed lines indicate the \pm $25 \%$ cutoffs for acceptable model fit. Ten replicate runs were conducted for each individual landscape.

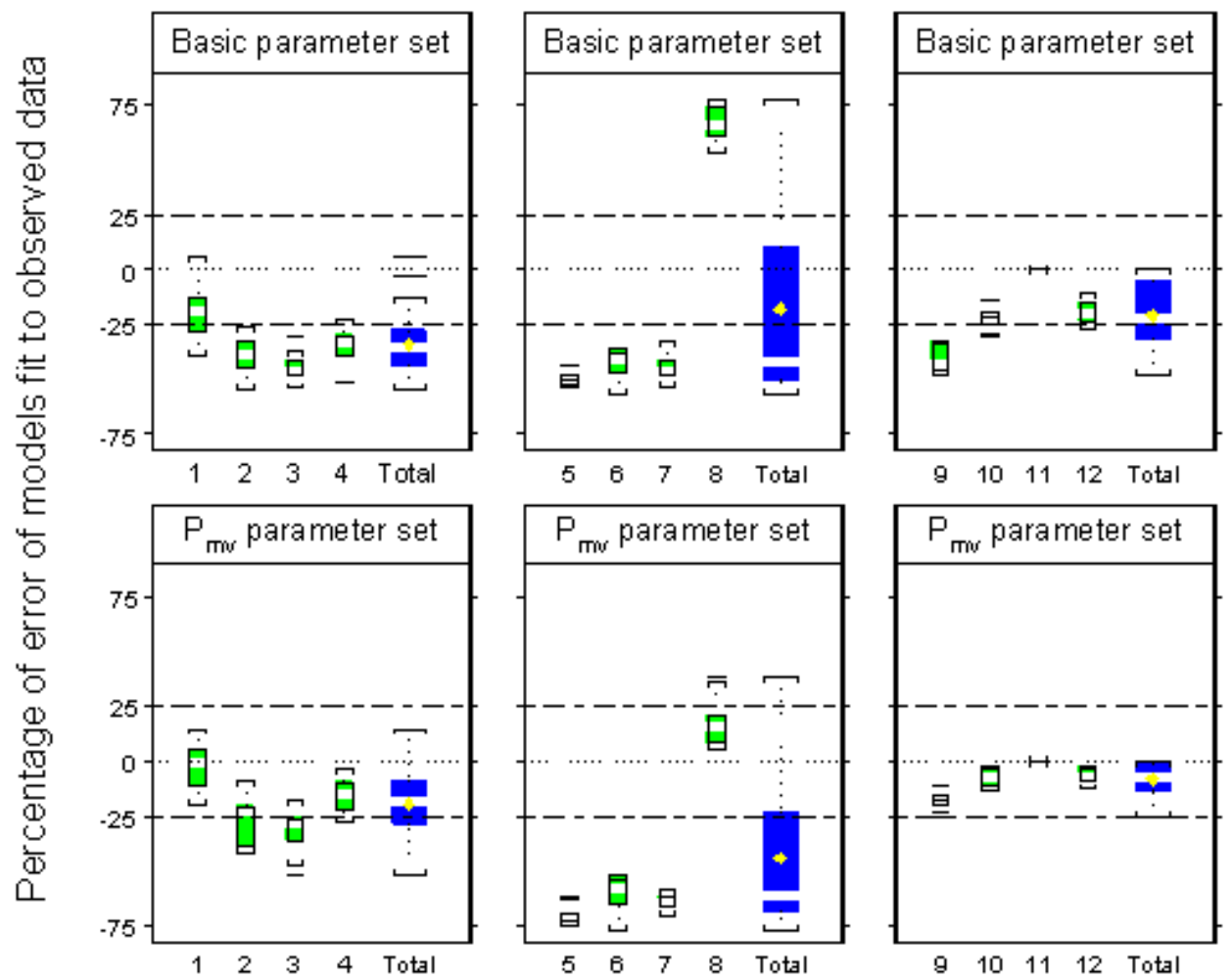


For C. maculata, the Both parameter set generated the model fit with the lowest percentage of error across all three landscape types (mean of absolute value of percentage of error pooled among landscape types: $19.7 \pm$ $15.2 \%$, mean \pm 1 SD) ( Fig. 6). There was, however, considerable variability in the percentage of error of model fit among replicate landscapes within the FO (22.9 $\pm 14.3 \%$, mean \pm 1 SD) and PF (30.6 $\pm 11.7 \%$, mean \pm 1 SD) landscape categories, but little variability among replicate NF landscapes (5.5 $\pm 4.7 \%$, mean \pm 1 SD) (Fig. 8). The latter result reflects the very low observed probability $(0.005)$ of damselflies leaving streams and hence locating and occupying the small amount of forest habitat present on some NF landscapes.

Fig. 8. Box plots displaying the percentage of error between predicted and observed proportions of Calopteryx maculata along stream habitat on individual landscapes, for the Both parameter set of the PERMEABILITY model. Individual boxes represent among-run variation in model fits on forested (FO), partially forested (PF), and nonforested (NF) landscapes. Total variation among individual landscapes within a landscape type is represented by the blue box (Total) in each panel. The numbers along the $x$-axes are individual landscape designations. See Fig. 7 legend for a description of the box plot display.
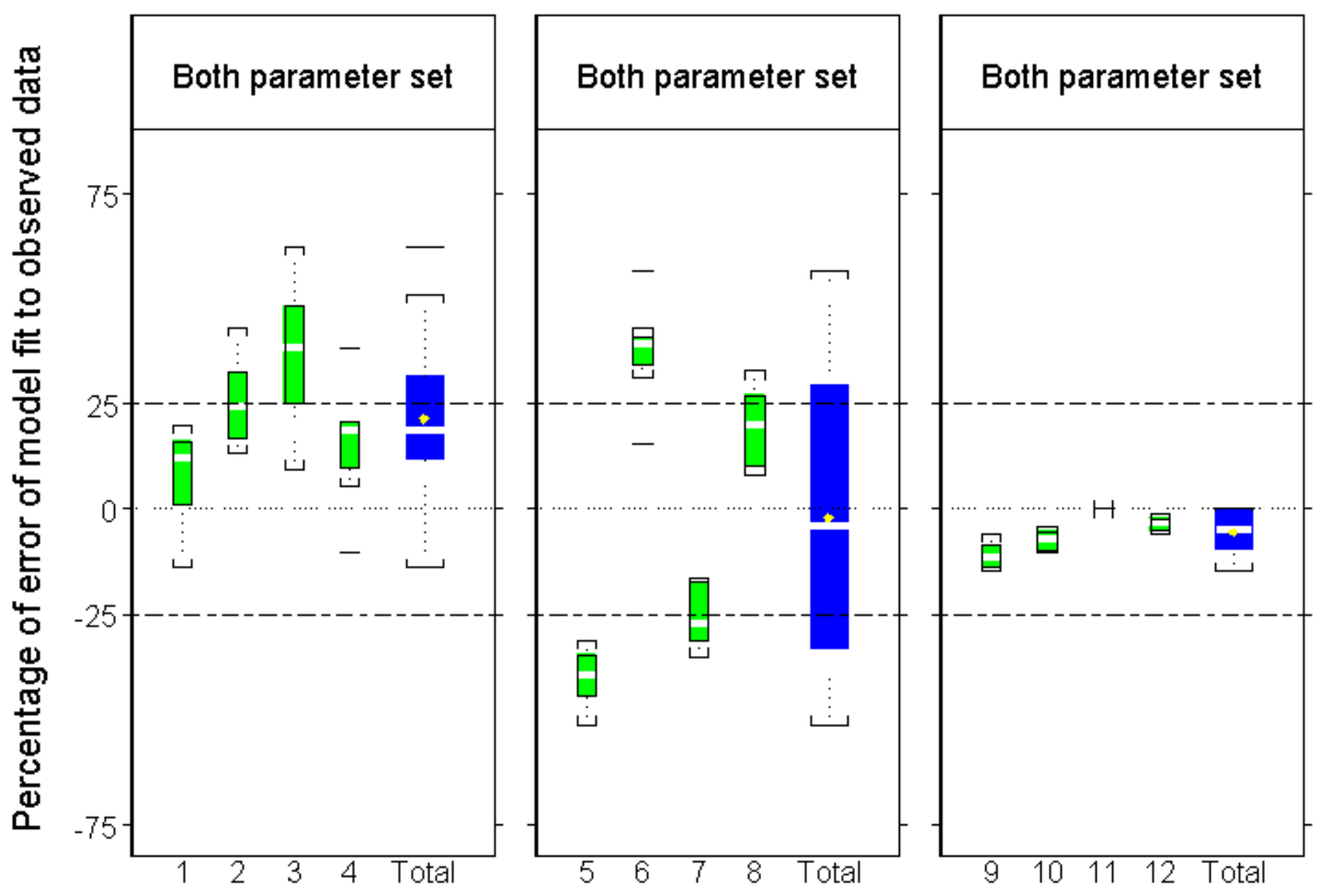

Individual landscapes 


\section{Simulation experiment}

Using the PERMEABILITY model, we conducted an experiment to assess the relative importance of patchspecific movement rates and stream boundary permeability (probability of moving off a stream) to $C$. maculata dispersion across a range of landscape structures. We were particularly interested in exploring how increased movement rates and directionality in pasture (relative to stream and forest habitats), in combination with various probabilities of moving off stream, would influence the ability of the PERMEABILITY model to predict observed distributions of C. maculata across the three landscape types. In other words, could the model generate adequate predictions with higher stream boundary permeabilities if patch-specific movement rates were altered?

In general, our simulation experiment results indicated that both patch-specific rates of movement ( $M$ ) and stream boundary permeability $\left(\mathrm{P}_{\mathrm{mv}}\right)$ were important determinants of damselfly distribution between stream

and forest habitat on heterogeneous landscapes (Fig. 9). When the probability of moving off stream was low to intermediate, the PERMEABILITY model predicted that a higher proportion of damselflies than the number actually observed would occupy stream habitat when movement rates and directionality were low in all three habitat types on FO and PF landscapes (Fig 9). However, when movement rates and directionality were moderately to substantially higher in pasture habitat, only the observed probability of moving off stream produced adequate model predictions (Fig. 9). As the probability of moving off stream increased, the model predicted progressively lower proportions of damselflies occupying stream habitat than were observed. In general, model predictions were closest to observed data at the empirically observed (lowest) value of $\mathrm{P}_{\mathrm{mv}}$ (on

each landscape type) combined with the low or intermediate values of $\mathrm{M}_{\text {stm }}$ (see Table 1 for movement

parameter values). Predicted proportions of C. maculata along streams on NF landscapes were in close agreement with observed data for the lowest levels of $M$ and $T$, regardless of the value of $P_{m v}(\underline{\text { Fig. } 9})$. This result

is a function of (1) low movement rates and directionality in all three habitats and (2) adjustments of predicted proportions of damselflies along streams for the number of damselflies occupying pasture. Damselflies moving at low rates and with little directionality generally were not able to locate the small amount of forest habitat on NF landscapes and consequently tended to occupy either stream or pasture habitat. Because we ignored damselflies occupying pasture when calculating proportions along streams (see Appendix 2), the proportion of damselflies along streams on NF landscapes was always near 1.

Fig. 9. Interaction plots of the percentage of error between predicted and observed proportions of Calopteryx maculata along stream habitat for four levels of stream boundary permeability or probability of moving off stream $\left(P_{m v}\right)$. Percentages of error are displayed according to levels of the move parameter $(\mathrm{M})$ in stream ( $\left.\mathrm{M}_{\text {stm }}\right)$, forest $\left(\mathrm{M}_{\text {for }}\right)$, and pasture $\left(\mathrm{M}_{\text {pas }}\right)$ and according to landscape type: forested (FO), partially forested (PF), and nonforested (NF). Note that only $M_{\text {stm }}$ and $P_{m v}$ parameters vary among landscape types. See Table 1 for turn concentration parameter ( $T$ ) values for each habitat type. Simulated data are from the PERMEABILITY model. Data points are mean percentage of error ([predicted - observed]/observed $\times 100$ ) based on four simulation runs per individual landscape for each combination of $\mathrm{P}_{\mathrm{mv}}$ and $\mathrm{M}$ values. The horizontal dotted line across each panel indicates perfect agreement between simulated and empirical data. The horizontal dashed lines at $\pm 25 \%$ across each panel indicate the cutoff between acceptable and poor model fit. 


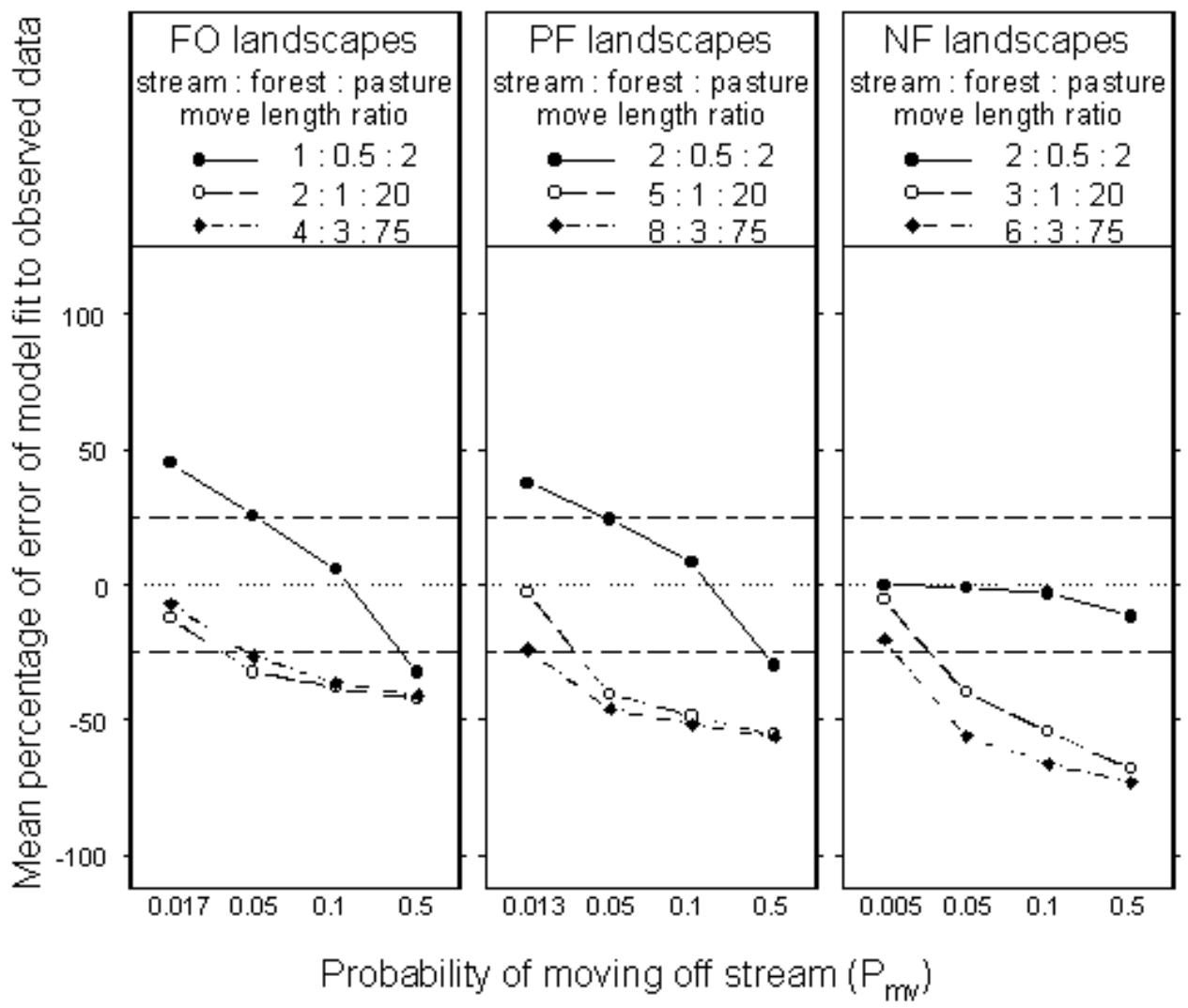

\section{SCUSSI ON}

\section{Empirical distributions}

Because adult emergence occurs along streams for both species (Martin 1939, J ohnson 1962), forest habitat is not occupied prior to the adult flight season. On partially forested landscapes, damselflies occupy both stream and forest habitats but do not appear to use other types of patches (Taylor and Merriam 1995), such as pasture or old fields. Because we know that both Calopteryx aequabilis and Calopteryx maculata are capable of moving from forest to stream through $700 \mathrm{~m}$ of forest or pasture (Pither and Taylor 1998), occupancy of forest habitat is an indication of movement between stream and forest.

Males and females of both species are distributed slightly differently among stream and forest resources, and abundances in both resources and on different landscapes vary throughout the day. Presumably, differences in resource use among the sexes arise from trade-offs between maximizing reproductive success and energy intake (e.g., Anholt 1992). Males increase their reproductive success by maintaining territories along streams and thus forgo foraging for extended periods (Waage 1973, Corbet 1980), whereas females increase their fecundity by foraging for extended periods in forest to facilitate oogenesis (Anholt 1992, Richardson and Baker 1997). Variation in abundance throughout the day may be a function of ambient temperature (e.g., Coxwell and Bock 1995, May 1995) or general behavioral patterns.

The most striking difference between the two species is that they are most abundant on landscapes at opposite extremes of habitat cover. C. aequabilis is most abundant on nonforested landscapes but rare on forested landscapes, whereas the opposite is true for C. maculata. Neither species tends to occupy forest on nonforested landscapes, suggesting that they must either use novel resources or fulfill all their lifehistory requirements solely along streams. Two results lend support to the latter conclusion: (1) neither species tends to move away from streams on nonforested landscapes (J onsen and Taylor 2000) and (2) both species occupy pasture transiently on partially forested landscapes (Taylor and Merriam 1995; I. D. Jonsen, personal observation). That C. maculata is rare on nonforested landscapes suggests that it cannot fulfill all its life-history requirements solely along streams and thus requires forest as an obligate resource, whereas $C$. aequabilis may use forest as a facultative resource. Alternatively, a competitive interaction between the two 
species, mediated by landscape structure, may limit the numbers of C. maculata on nonforested landscapes and C. aequabilis on forested landscapes. Another alternative is that between-species differences in adult distributions along a forest cover gradient may reflect the distribution of suitable habitats for their aquatic larval stages. However, we have no evidence to support or refute either of these alternate scenarios.

\section{Simulations}

The key result from our simulations is that damselfly landscape-level dispersions appear to arise from movement responses to both within-patch characteristics and to a broader scale feature of the landscape (i. e., amount of forest habitat). If movements were simply responses to fine-scale habitat structure, then we would expect differences in patch mosaics to be the main factor influencing differences in broader scale dispersions among landscapes. If this were the case, our simulations would adequately predict damselfly dispersions without having to account for landscape-specific influences on fine-scale movement behaviors (i.e., the PERMEABILITY model using the Basic parameter set would suffice). However, our results suggest that dispersions can be predicted adequately only when both patch-specific and landscape-specific influences on finescale movements are taken into account (the PERMEABILITY model using the $\mathrm{P}_{\mathrm{mv}}$ parameter set for $\mathrm{C}$.

aequabilis and the Both parameter set for C. maculata). In other words, damselflies appear to perceive habitat structure at multiple spatial scales and respond by altering their fine-scale movement behavior.

Another way of thinking about this multiscale effect of habitat characteristics on movement and dispersion is that animals may respond either "passively" or "actively" to landscape structure. A passive response occurs when animals perceive and respond only to within-patch and patch boundary stimuli. In this scenario, animals are blind to broader scale stimuli, and movement behaviors differ only among habitat patches of different types. Consequently, different movement patterns and dispersions will arise only on landscapes with sufficiently different types of habitats and/or spatial configurations (e.g., Gustafson and Gardner 1996). In contrast, an active response will occur when animals perceive and respond not only to within-patch and patch boundary stimuli but also to broader scale stimuli, such as the amount of habitat on a landscape. Animals integrate both fine and broader scale stimuli, and movement behaviors differ not only among different types of habitat patches but also among similar habitat patches embedded on different types of landscapes (e.g., a partially fragmented vs. a highly fragmented landscape). In this scenario, different movement patterns and dispersions may arise on more similarly structured landscapes. For example, the partially forested and "nonforested" landscapes used in this study are similar in structure; both contain a stream flowing through pasture with some amount of forest habitat isolated from the stream. The probability of leaving the stream differs between these two landscape types, even though the stream habitat and stream-pasture boundary are the same on both landscapes (J onsen and Taylor 2000). Our simulation results suggest that these differences in movement behaviors among both patch and landscape types lead to the observed differences in landscapelevel distributions.

Others have suggested that perceptual range may have important implications, via its influence on movement behavior, for population distribution and dynamics (With 1994a, Lima and Zollner 1996, Zollner and Lima 1999). Our results suggest that damselfly perceptual ability (1) is an important component of movementspatial structure interactions and (2) influences broader scale patterns of distribution.

Evaluation of our simulation models revealed that damselfly distributions could only be adequately predicted when information about movement rates in different habitats and responses to patch boundaries was incorporated. Our VISCOSITY model, which represented damselfly movement simply as variation in move lengths and turn angles among different habitats, was unable to adequately predict dispersions of either species. A conceptually similar, spatially implicit diffusion-approximation model (Turchin 1991) predicted dispersions on completely forested landscapes (data not presented) similar to those obtained using our VISCOSITY model. Only when a patch boundary behavior (the probability of moving off stream) was incorporated into our PERMEABILITY model were predicted and observed dispersions more closely matched. By varying habitatspecific movement rates and stream boundary permeability, we did find slight evidence that suggests that, when movement rates are sufficiently low in all three habitats, the importance of the patch boundary parameter on dispersions may be reduced (see the filled circles in Fig. 9). This probably occurs because damselflies do not encounter stream boundaries as often because of low movement rates in stream habitat. Alternatively, damselflies venturing away from a stream have an increased probability of returning to that stream simply because their rates of movement do not result in large displacements away from stream habitats. Nevertheless, our simulation experiment indicated that both movement parameters were generally required to predict observed patterns of distribution. Patch boundary permeability may be less important to animals that have an average move length much smaller than the size of the habitat patch they are moving through (e.g., damselflies moving through forest habitat; see below).

Adequate predictions of C. maculata dispersions were achieved only when broader scale landscape effects on both the probability of moving off stream and on stream movement rates were considered. This was not the case, however, for $\mathrm{C}$. aequabilis, where model predictions were closest to observed data when either no landscape effects or only the landscape effect on the probability of moving off stream were taken into account. These findings are consistent with results elsewhere indicating that landscape type strongly influences the ability of C. maculata to move both at broad scales (i.e., $700 \mathrm{~m}$ ) and at finer scales (i.e., 10-100 m), but has only a slight influence on the ability of C. aequabilis to move at either broad or finer scales (Pither and Taylor 1998, 
Jonsen and Taylor 2000). Furthermore, the probability of moving away from streams for both species was strongly influenced by landscape type (J onsen and Taylor 2000), a result that is in general agreement with our simulations.

Using a similar modeling approach, With and Crist $(1995,1996)$ found that their simulations of finescale grasshopper movements could predict the type of broader scale dispersion (i.e., aggregated vs. random) observed, but could not predict quantitatively the observed levels of aggregation. They suggested that grasshopper movements were constrained by processes operating at different scales, so that it was difficult to make quantitative predictions of dispersion using only fine-scale movement information. In a way, our results provide some corroboration of their conclusion. Because our simulations modeled movement over a single day, our results showed that, in the general absence of potentially constraining factors such as mortality and weather, damselfly dispersions could be predicted on average from fine-scale movement behaviors, but only when the influence of the broader landscape on these behaviors was taken into account. Furthermore, our model calibrations (not presented) revealed that, as we increased simulation duration beyond a few days, our models predicted that nearly all damselflies would occupy forest habitat and that very few would be found along streams. However, in reality, Calopteryx damselflies are strongly tied to stream habitat. Sexually mature males defend breeding territories along streams and are largely precluded from moving away from streams, whereas immature adults and mature females may forage away from streams but must return to mate or oviposit (Johnson 1962, Waage 1972). Therefore, over longer time periods, the fine-scale movements we simulated may be constrained by factors such as physiological state, sex, and predation risk.

In our simulations, movements back to streams occurred simply by chance, but we suspect that there is a specific behavior or suite of behaviors that allows damselflies to return to their natal streams with greater frequency than can be predicted by chance alone. Inclusion of a forest boundary permeability parameter for movements from forest to pasture or stream would be one way to alter the probabilities of returning to streams. However, because movement rates were lowest in forest (Fig. 3), the probability of encountering a forest boundary should be much lower than for movements in pasture and stream habitats. Therefore, it is unlikely that a forest boundary permeability parameter would enhance long-term predictions of movements back to streams, because this parameter can constrain movements only across a forest boundary (i.e., in the simulations presented here, the probability of crossing a forest boundary was effectively 1).

One feature of our study that sets it apart from other landscape-level simulation studies is that we tested model predictions on 12 separate landscapes, four in each of three levels of forest cover. Our results indicated considerable variability among individual landscapes, especially with the partially forested level (Fig. 7 and Fig. 8). This residual variation in model fit may be because of differences in the configuration of forest habitat among individual landscapes or to differences in finer scale attributes (or both). Variability among landscapes in both broad- and fine-scale factors, combined with the influence of landscape structure on finescale movements (Wiens et al. 1997, Jonsen and Taylor 2000), suggests that studies of this type may benefit from replication at landscape scales where feasible.

Despite the acknowledged potential limitation of vector-based movement (Appendix 2), our PERMEABILITY model adequately predicts damselfly dispersions, on average, across the range of landscapes studied. This suggests that defining damselfly movements based on 1-min intervals sufficiently captures the range of movements that contribute to patterns of distribution on the landscapes studied here. Nevertheless, the behavior of vector-based movement models merits further exploration to determine the generality of their application to other animal systems.

\section{SPECULATI ON}

The key result emerging from our simulations suggests that patterns of damselfly distribution may arise from multiscale responses to habitat structure. In other words, damselflies alter their fine-scale movement behavior when encountering and moving through different patch types, but these responses are further modified by features of the broader landscape (e.g., amount of suitable habitat). Our simulations showed that patterns of distribution could be predicted from fine-scale movement behaviors only when these multiscale responses were considered.

Our simulated distributions were not population-level equilibrium patterns, but rather daily landscape-scale ones. Observations of Calopteryx movements (Taylor and Merriam 1995, Pither and Taylor 1998) suggest that, in reality, the scale of individual local populations may extend farther away from streams (i.e., up to or beyond $750 \mathrm{~m}$ ) than it does in either our simulation landscapes (about $500 \mathrm{~m}$ from stream) or empirical surveys in forest habitat (50-500 m from stream), although it is not clear how long a stretch of stream habitat is required to encompass a local population of breeding individuals. Nevertheless, we suggest that our results do have implications for population-level distributions and broad-scale population dynamics.

For example, damselflies must move further away from streams to access forest habitats on landscapes where stream and forest are isolated. All else being equal, we expect that foraging individuals on partially 
forested landscapes may have a greater probability of interacting with other local populations than do individuals on completely forested or nonforested landscapes (individuals on nonforested landscapes rarely move away from streams). In other words, landscape structure may mediate the exchange of individuals among local populations via its interaction with fine-scale movements. Such predictions remain largely untested, but illustrate how landscape patterns may affect metapopulation-type dynamics.

\section{RESPONSES TO THIS ARTI CLE}

Responses to this article are invited. If accepted for publication, your response will be hyperlinked to the article. To submit a comment, follow this link. To read comments already accepted, follow this link.

\section{Acknowledgments:}

We are grateful to several landowners for access to their land. Heather Forsyth, Erik Barr, Nicole Humble, Tina Moore, Trish Turliuk, J en Cookson, Manny Plourde, Amy Ferguson, and Gray Merriam provided valuable field assistance. Brett Goodwin, F.R. Adler, R. Peet, and D. Baldwin commented on previous versions of this manuscript. IDJ was funded by an Acadia University Graduate Fellowship and an Alden B. Dawson Research Scholarship. PDT was funded by NSERC and Environment Canada through their support of the Atlantic Cooperative Wildlife Ecology Research Network (ACWERN). Additional facilities were provided by Jens Roland and Robert Bourchier.

\section{TERATURE CITED}

Addicott, J. F., J. M. Alho, M. F. Antolin, D. K. Padilla, J. S. Richardson, and D. A. Soluk. 1987. Ecological neighborhoods: scaling environmental patterns. Oikos 49: 340-346.

Anholt, B. R. 1992. Sex and habitat differences in feeding by an adult damselfly. Oikos 65: 428-432.

Batschelet, E. 1980. Circular statistics in biology. Academic Press, London, UK.

Corbet, P. S. 1980. Biology of Odonata. Annual Review of Entomology 25: 189-217.

Coxwell, C. C., and C. E. Bock. 1995. Spatial variation in diurnal surface temperatures and the distribution and abundance of an alpine grasshopper. Oecologia 104: 433-439.

Fahrig, L., and G. Merriam. 1985. Habitat patch connectivity and population survival. Ecology 66: $1762-1768$.

Fahrig, L., and J. Paloheimo. 1988. Effect of spatial arrangement of habitat patches on local population size. Ecology 69: 468-475.

Forsyth, A., and R. D. Montgomerie. 1987. Alternative reproductive tactics in the territorial damselfly Calopteryx maculata: sneaking by older males. Behavioral Ecology and Sociobiology 21: 73-81.

Gustafson, E. J ., and R. H. Gardner. 1996. The effect of landscape heterogeneity on the probability of patch colonization. Ecology 77: 94-107.

Hanski, I . 1994. A practical model of metapopulation dynamics. Journal of Animal Ecology 63: 151-162.

Johnson, A. R., B. T. Milne, and J . A. Wiens. 1992. Diffusion in fractal landscapes: simulations and experimental studies of Tenebrionid beetle movements. Ecology 73: 1968-1983.

Johnson, C. 1962. Breeding behavior and oviposition in Calopteryx maculatum (Beauvois) (Odonata: Calopterygidae). American Midland Naturalist 69: 242-247.

J onsen, I. D., and P. D. Taylor. 2000. Fine-scale movement behaviors of Calopterygid damselflies are influenced by landscape structure: an experimental manipulation. Oikos 88: 553-562. 
Kareiva, P. 1987. Habitat fragmentation and the stability of predator-prey interactions. Nature 326: $388-390$.

Lele, S., M. L. Taper, and S. Gage. 1998. Statistical analysis of population dynamics in space and time using estimating functions. Ecology 79: 1489-1502.

Lima, S. L., and P. A. Zollner. 1996. Towards a behavioral ecology of ecological landscapes. Trends in Ecology and Evolution 11: 131-135.

Mathsoft. 1999. S-Plus 2000 user's guide. Mathsoft, Seattle, Washington, USA.

Martin, R. D. C. 1939. Life histories of Agrion aequabile and Agrion maculatum (Agriidae: Odonata). Annals of the Entomological Society of America 32: 601-619.

May, M. L. 1995. Simultaneous control of head and thoracic temperature by the green darner dragonfly Anax junius (Odonata: Aeshnidae). Journal of Experimental Biology 198: 2373-2384.

McCullagh, P., and J. A. Neldar. 1989. Generalized linear models. Second edition. Chapman and Hall, London, UK.

Moilanen, A. and I. Hanski. 1998. Metapopulation dynamics: effects of habitat quality and landscape structure. Ecology 79: 2503-2515.

Odendaal, F. J., P. Turchin, and F. R. Stermitz. 1989. Influence of host-plant density and male harassment on the distribution of female Euphydryas anicia (Nymphalidae). Oecologia 78: 283-388.

Pither, J., and P. D. Taylor. 1998. An experimental assessment of landscape connectivity. Oikos 83: $166-174$.

Richardson, J. M. L., and R. L. Baker. 1997. Effect of body-size and feeding on fecundity in the damselfly Ischnura verticalis (Odonata: Coenagrionidae). Oikos 79: 477-483.

Roitberg, B. D., and M. Mangel. 1997. Individuals on the landscape: behavior can mitigate landscape differences among habitats. Oikos 80: 234-240.

Schippers, P., J. Verboom, J. P. Knaapen, and R. C. van Apeldoorn. 1996. Dispersal and habitat connectivity in complex heterogeneous landscapes: an analysis with a GIS-based random walk model. Ecography 19: $97-106$.

Schumaker, N. H. 1996. Using landscape indices to predict habitat connectivity. Ecology 77: 1210-1225.

Stamps, J. A., M. Buechner, and V. V. Krishnan. 1987. The effects of edge permeability and habitat geometry on emigration from patches of habitat. American Naturalist 129: 533-552.

Taylor, P. D., L. Fahrig, K. Henein, and G. Merriam. 1993. Connectivity is a vital element of landscape structure. Oikos 68: 571-573.

Taylor, P. D., and G. Merriam. 1995. Wing morphology of a forest damselfly is related to landscape structure. Oikos 73: 43-48.

Turchin, P. 1991. Translating the foraging movements in heterogeneous environments into the spatial distribution of foragers. Ecology 72: 1253-1266.

Turchin, P. 1998. Quantitative analysis of movement: measuring and modeling population redistribution in animals and plants. Sinauer, Sunderland, Massachusetts, USA.

Waage, J. K. 1972. Longevity and mobility of Calopteryx maculata (Beauvois, 1805) (Zygoptera: Calopterygidae). Odonatologica 3: 155-162.

Waage, J. K. 1973. Reproductive behavior and its relation to territoriality in Calopteryx maculata (Beauvois) (Odonata: Calopterygidae). Behavior 487: 240-256.

Wiens, J. A. 1997. Metapopulation dynamics and landscape ecology. Pages 43-62 in I. A. Hanski and M. E. Gilpin, editors. Metapopulation biology: ecology, genetics and evolution. Academic Press, Toronto, Canada.

Wiens, J. A., and B. T. Milne. 1989. Scaling of "landscapes" in landscape ecology, or, landscape ecology from a beetle's perspective. Landscape Ecology 3: 87-96. 
Wiens, J. A., R. L. Schooley, and R. D. Weeks, J r. 1997. Patchy landscapes and animals movements: do beetles percolate? Oikos 78: 257-264.

With, K. A. 1994a. Using fractal analysis to assess how species perceive landscape structure. Landscape Ecology 9: $25-36$.

With, K. A. 1994b. Ontogenetic shifts in how grasshoppers interact with landscape structure: an analysis of movement patterns. Functional Ecology 8: 477-485.

With, K. A., and T. O. Crist. 1995. Critical thresholds in species' responses to landscape structure. Ecology 76: 2446-2459.

With, K. A., and T. O. Crist. 1996. Translating across scales: simulating species distributions as the aggregate response of individuals to heterogeneity. Ecological Modelling 93: 125-137.

With, K. A., R. H. Gardner, and M. G. Turner. 1997. Landscape connectivity and population distributions in heterogeneous environments. Oikos 78: 151-169.

With, K. A., S. J . Cadaret, and C. Davis. 1999. Movement responses to patch structure in experimental fractal landscapes. Ecology 80: 1340-1353.

Zollner, P. A., and S. L. Lima. 1997. Landscape-level perceptual abilities in white-footed mice: perceptual range and the detection of forested habitat. Oikos 80: 51-60.

Zollner, P. A., and S. L. Lima. 1999. Search strategies for landscape-level interpatch movements. Ecology 80: 1019-1030.

\section{APPENDIX 1}

Images of a male Calopteryx aequabilis (left) and a male Calopteryx maculata (right). Both species are similar in size, despite scale differences between the images. [ERRATUM: These figures were published without attribution to the original source. They are reproduced now with permission from the photographer Mark $\mathrm{F}$. O'Brien, Museum of Zoology, University of Michigan.]
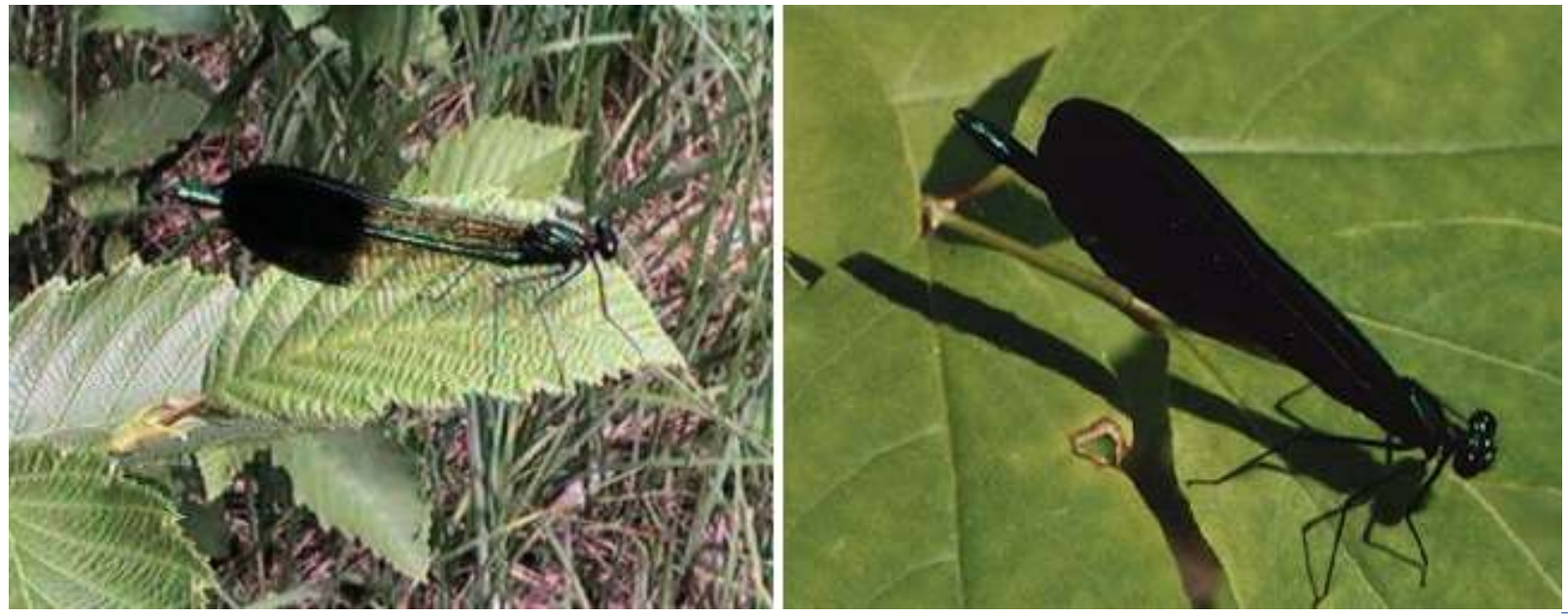

\section{APPENDIX 2}

Simulation model details.

To keep the models as simple as possible, we made two assumptions common to both. First, we represented damselfly movement over landscapes by a random series of habitat-specific move lengths and turn angles. Moves were defined as the straight-line distance traveled during a 1-minute interval. This time step corresponds to empirical measures of damselfly movement (Jonsen and Taylor 2000). Second, we assumed that Calopteryx aequabilis and Calopteryx maculata used only stream and forest as habitats and moved through all other elements of the landscape as they do through pasture. For the purpose of this study, we treated 
all nonhabitat elements as though they were pasture. We did this for two reasons: (1) pasture was the only nonhabitat element for which we had movement data, and (2) pasture dominated (about 65\%) the nonhabitat components on all 15 landscapes. Other nonhabitat elements presented on some landscapes included houses, hay and small-grain fields, and clearcuts.

At the outset of each simulation run, 100 damselflies were placed randomly along a central portion of the stream habitat. Damselflies were constrained to move in discrete steps of 1-minute intervals. The former condition was intended to mimic the initial distribution of emerging adults at the beginning of the breeding season, i.e., adult emergence occurs solely along streams (Martin 1939, J ohnson 1962), whereas the latter condition mimicked an empirical analysis of damselfly movement (Jonsen and Taylor 200).

In both models (VISCOSITY and PERMEABILITY), move lengths and turn angles were drawn randomly from empirically determined distributions for each habitat type. In the VISCOSITY model, individuals redistributed themselves freely over the landscape according to habitat-specific movement parameters. In the PERMEABILITY model, movements away from streams were restricted so that, in any time step, the probability of individual damselflies moving off stream matched an empirically observed probability $(P$ mv $)$. Once a

damselfly moved off stream, it moved freely over the landscape (as in the VISCOSITY model), unless it re-encountered the stream.

Movement pathways were represented as a series of connected vectors, each of length $M$ and direction $T$. At the end of each move, the vector defined by the scalars $M_{R}$ and $T_{R}$ was converted to $x, y$ integers to correspond with

the landscape grid. The habitat type of the cell at position $\mathrm{x}, \mathrm{y}$ was evaluated, and the appropriate move and turn distributions were specified for the next move. Successive moves $\left(M_{i}, T_{i}\right)$ were added onto the resultant $M_{R}$ '

$T_{R}$ calculated in the previous time step (not the $x, y$ integer position) (see Appendix 4 for a visualization). At the

end of each simulation run, we calculated the proportions of damselflies occupying stream and forest habitats and compared them with observed proportions from our survey data. Damselflies occupying pasture at the end of simulations were removed (i.e., assumed to be dead), and proportions in stream and forest were adjusted accordingly.

The use of vector-based movements has one potential limitation: vector-based moves can pass directly through a habitat patch if the move does not begin or terminate in that patch. In other words, damselflies moving through a patch do not alter their behavior unless the current move terminates and a new move initiates in that patch. Despite this potential limitation, we chose to use vector- rather than cell-based movement because it related directly to (1) damselfly movements measured in the field (Jonsen and Taylor 2000) and (2) correlated random walk processes, which are often used as null models of insect movement (Turchin 1998).

Based on model calibration tests (not presented), we chose 480 time steps ( $8 \mathrm{~h}$ ) as a maximum duration for simulation runs. This approximated the daily activity period for both $\mathrm{C}$. aequabilis and C. maculata (Waage 1972). We used reflecting borders for all simulations.

To correspond with our survey design (no transects through pasture), we corrected the predicted proportions of damselfly in stream and forest for individuals that were in pasture at the end of simulation runs. We did this by subtracting the number in pasture from 100 and using this difference to calculate the proportions in stream and forest habitats. Thus, the proportions of $\mathrm{C}$. aequabilis and $\mathrm{C}$. maculata in forest were equal to 1 minus the proportions along streams. For brevity, we present only data pertaining to stream habitat.

Although our models predicted the proportions of damselflies in stream and forest habitats, our observed proportions were based on damselfly counts along stream and forest transects. Because our forest transects sampled a smaller proportion of habitat than did our stream transects, we adjusted counts in forest relative to the proportion of total stream area sampled as follows:

$\left(1200 \mathrm{~m}^{2} /\right.$ total area of stream) $\times$ total area of forest $\times$ (observed counts in forest/2000 $\mathrm{m}^{2}$ )

where $1200 \mathrm{~m}^{2}$ and $2000 \mathrm{~m}^{2}$ are the areas encompassed by stream and forest transects, respectively.

\section{APPENDIX 3}

Summary table of the VISCOSITY and PERMEABILITY simulation models along with the parameter sets used for 
each. The parameter sets are: Basic, parameters are invariant among landscape types; M $_{\text {Stm' }}$ stream move length distributions vary among landscape types; $\mathrm{P}_{\mathrm{mv}}$, probabilities of moving off stream vary among landscape types; Both, both stream move length distributions and probabilities of moving off stream vary among landscape types.

\begin{tabular}{|c|c|c|c|c|c|c|}
\hline \multirow{2}{*}{$\begin{array}{c}\text { Model } \\
\begin{array}{c}\text { Parameter } \\
\text { set }\end{array}\end{array}$} & \multicolumn{2}{|c|}{ VISCOSITY } & \multicolumn{4}{|c|}{ PERMEABI LITY } \\
\hline & Basic & $\mathrm{M}_{\text {stm }}$ & Basic & $\mathrm{P}_{\mathrm{mv}}$ & $\mathrm{M}_{\text {stm }}$ & Both \\
\hline $\begin{array}{l}\text { Movement } \\
\text { process }\end{array}$ & \multicolumn{2}{|c|}{$\begin{array}{l}\text { Random draws from empirical move and } \\
\text { turn distributions (patch viscosity) }\end{array}$} & \multicolumn{4}{|c|}{$\begin{array}{l}\text { Random draws from empirical move and turn distributions (patch } \\
\text { viscosity), movements away from streams constrained by probability of } \\
\text { moving off stream (patch boundary permeability) }\end{array}$} \\
\hline $\begin{array}{l}\text { Move/ turn } \\
\text { distributions } \\
\text { (habitat- } \\
\text { specific) }{ }^{\dagger}\end{array}$ & $\begin{array}{l}\text { Constant among } \\
\text { landscapes }\end{array}$ & $\begin{array}{l}\text { Stream moves vary } \\
\text { among landscapes }\end{array}$ & Constant am & g landscapes & $\begin{array}{r}\text { Stream move } \\
\text { land }\end{array}$ & $\begin{array}{l}\text { lary among } \\
\text { pes }\end{array}$ \\
\hline $\begin{array}{c}\text { Stream } \\
\text { boundary } \\
\text { permeability }\end{array}$ & \multicolumn{2}{|c|}{ Not applicable } & $\begin{array}{l}\text { Probability } \\
\text { constant among } \\
\text { landscapes }\end{array}$ & $\begin{array}{l}\text { Probability varies } \\
\text { among } \\
\text { landscapes }\end{array}$ & $\begin{array}{l}\text { Probability } \\
\text { constant among } \\
\text { landscapes }\end{array}$ & $\begin{array}{l}\text { Probability } \\
\text { varies among } \\
\text { landscapes }\end{array}$ \\
\hline
\end{tabular}

+ Move length distributions in forest and pasture habitat and turn-angle distributions in all habitats are constant among landscape types, for all parameter sets.

\section{APPENDIX 4}

Example of simulated damselfly movement over a digitized landscape. The left image displays a single pathway initiated at the stream (blue), traversing pasture (grey), and terminating in forest (green). A single move, defined by 1-min time steps, is illustrated by the yellow line segment. The two possible stream boundary responses (crossed/not crossed) are illustrated in the right image.

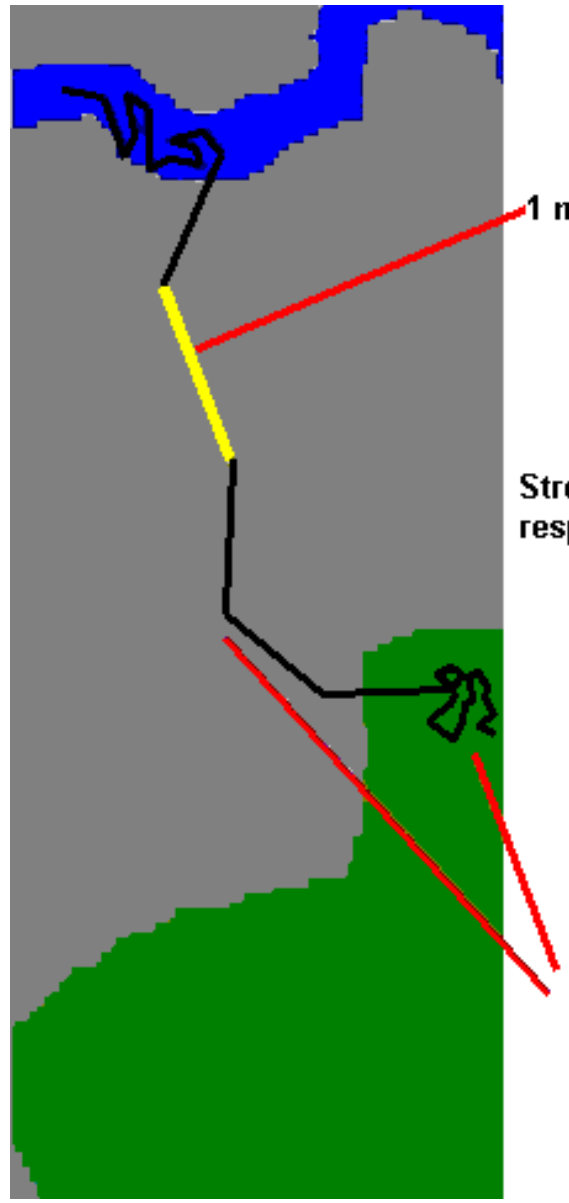

Different habitat viscosities

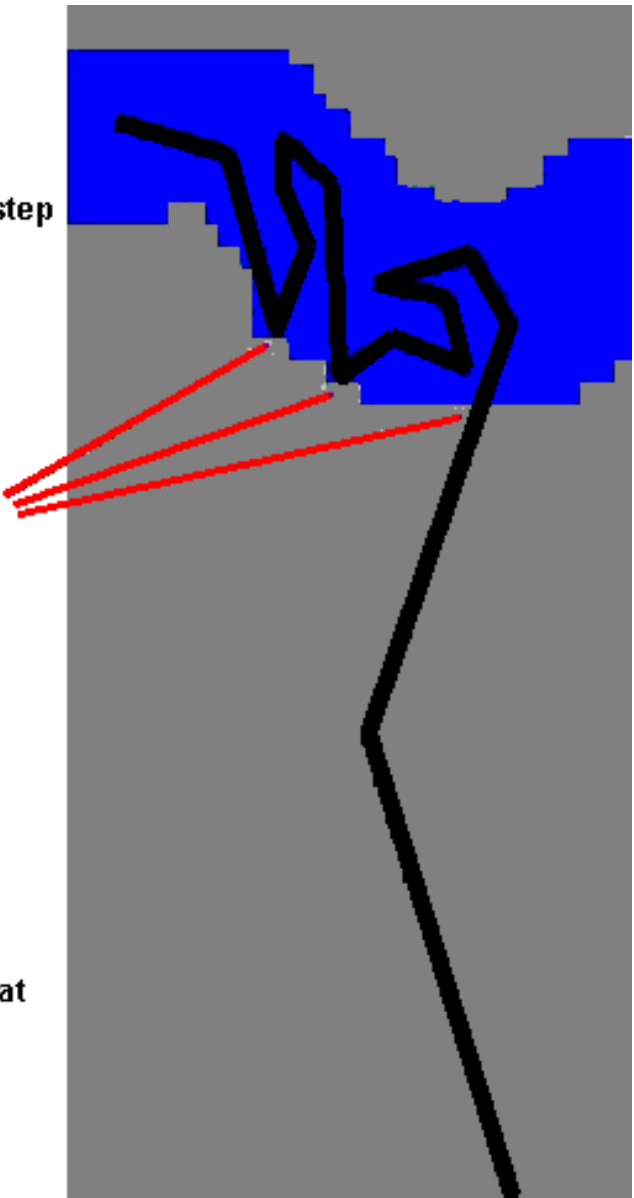




\section{Address of Correspondent:}

Ian Jonsen

Lethbridge Research Centre

Lethbridge, Alberta, Canada T1J 4B1

Phone: (403) 3173308

Fax: (403) 3823156

jonseni@em.agr.ca

Home | Archives | About | Login | Submissions | Notify | Contact | Search 